\title{
SOBRE LA ARTICULACIÓN DE ORDENAMIENTOS EN LA UNIÓN EUROPEA. A PROPÓSITO DEL LIBRO TRANSPOSICIÓN DE DIRECTIVAS Y AUTOGOBIERNO COORDINADO POR XABIER ARZOZ SANTISTEBAN ${ }^{1}$
}

\author{
JORGE ALGUACIL GONZÁLEZ-AURIOLES \\ Profesor Contratado Doctor de Derecho constitucional \\ Departamento de Derecho Político. UNED
}

SUMARIO

I. Introducción: sobre la importancia del libro coordinado por Xabier Arzoz.

II. El estudio teórico.

III. Los estudios comparado y empírico.

IV. El diagnóstico y las propuestas de mejora.

$\mathrm{V}$. A modo de conclusiones.

\section{INTRODUCCIÓN: SOBRE LA IMPORTANCIA DEL LIBRO COORDINADO POR XABIER ARZOZ}

Konrad Hesse, seguramente el más importante iuspublicista alemán del siglo pasado, en el contexto del análisis de las tareas fundamentales de la Constitución, resulta categórico: «allí donde, partiendo de la pluralidad de voluntades, ya no es posible formar una voluntad conjunta vinculante, y allí donde ya no se consiga establecer y realizar por la vía del entendimiento o de las decisiones mayoritarias los objetivos políticos, quiebra el Estado como unidad política de acción» ${ }^{2}$. Como es

1 ARZOZ SANTISTEBAN, X. (dir), Transposición de directivas y autogobierno. Un desarrollo normativo del Derecho de la Unión Europea en el Estado autonómico, Barcelona: Institut d'Estudis Autonómics, 2013.

2 HESSE, K., «Constitución y Derecho constitucional», BENDA, E.; VOGEL, H.; HESSE, K.; HEYDE, W., Manual de Derecho Constitucional, Madrid. Barcelona: Marcial Pons, 2001, p. 3. Un análisis particularmente lúcido de la figura de Konrad Hesse y de la repercusión de su dogmática en el orden constitucional alemán y europeo podemos encontrarlo en GUTIÉRREZ GUTIÉRREZ, I., «Gestación, recepción y vigencia: la teoría de la Constitución y el Derecho constitucional de Konrad Hesse», Revista Española de Derecho Constitucional ${ }^{\circ}$ 100, 2014. 
conocido, tal tarea integradora se proyecta al menos en tres ámbitos: en la necesidad de establecer la legitimidad democrática de todo poder político, en la de garantizar una posición subjetiva a los individuos y a los grupos, y en la de ordenar la organización política, tanto estructuralmente como territorialmente. Centrándonos en la tercera de las tareas, el pluralismo territorial en organizaciones políticas que abarcan realidades geográficas, culturales e incluso lingüísticas diferentes, resulta especialmente complejo. Tales dificultades no son menores: por eso suele decirse que cualquier sistema de organización territorial del poder requiere, cuando menos, de una garantía política de la descentralización y de una determinada cultura o espíritu federal que lo haga posible.

La garantía política de la descentralización suele cifrarse, entre otras cosas, en la existencia de una segunda cámara legislativa que permita articular la representación de los entes descentralizados en el seno de la Federación; para permitir su participación en la voluntad de la Federación y a los efectos de ofrecer un espacio político donde quepa conciliar los diversos intereses eventualmente dispares entre los propios entes descentralizados y entre los entes descentralizados y la Federación ${ }^{3}$. Una de las proyecciones más afortunadas de la cultura o espíritu federal lo acuñó el constitucionalismo alemán con el conocido principio de lealtad federal. Hesse cifró tal principio en su conocida publicación El Estado Unitario Federal como una de las piezas centrales del ordenamiento del Estado federal alemán, si bien alertó frente a un quizá excesivo uso que del mismo había realizado el Tribunal Constitucional Federal alemán ${ }^{4}$.

Es cierto que la Constitución española no articula la segunda cámara legislativa como una verdadera cámara de representación de los entes descentralizados; y que tampoco contempla el principio de lealtad federal, siendo quizá más adecuado en nuestro ordenamiento hablar de lealtad constitucional ${ }^{5}$. Las carencias descritas, junto con la propia deficiencia en la configuración del propio Título VIII CE, convierten nuestro sistema territorial en especialmente problemático. Y sitúan, como es conocido, al Tribunal Constitucional en una muy delicada situación ${ }^{6}$. En cualquier caso, puede entenderse que uno u otro principio imponen al Estado y

3 Para HESSE la existencia de la cámara de representación territorial es acorde con la idea del Estado federal unitario, y no supone un desmonte del orden federal, sino su reforzamiento, HESSE, K., «El Estado Federal Unitario», Revista de Derecho Constitucional Europeo, n 6, pp. 18, 19, 20.

4 HESSE, K., «El Estado Federal Unitario», Revista de Derecho Constitucional Europeo, n 6, pp. 7, 8, 9. La excesiva judicialización de tal principio y en general del papel de la justicia constitucional en la resolución de los conflictos en el Estado federal son vistos por Hesse como una clara amenaza: «La unidad o la decisión política, elementos esenciales del proceso político contemporáneo ideado por la Constitución, serán sustituidos por decisiones del Tribunal Constitucional — perjudicando la política, el Derecho y los tribunales, que tiene mucho que perder: la política porque se ve recortada en su elemento esencial, el Derecho porque es sobre-exigido, y el Tribunal Constitucional porque ha de responder a cuestiones que le son extrañas», p. 9.

5 BIGLINO CAMPOS, P., «La lealtad constitucional en el Estado de las Autonomías», Revista Jurídica de Castilla y León número extraordinario enero de 2004, pp. 57, 58.

6 El Tribunal Constitucional asume una doble función: de un lado, una tarea cuasi_legisladora para concretar estas normas y hacerlas aplicables; de otro, actúa como órgano regulador de los conflictos que la dinámica en cuestión genera, pues no ha creado la Constitución un órgano político en cuyo seno pueda recon- 
a las Comunidades Autónomas al menos dos deberes: el de mantenerse dentro de sus propias competencias, y la obligación de ejercer las propias funciones teniendo en cuenta la recíproca dependencia existente entre ambas entidades territoriales; la cooperación entre entes descentralizados habría de ser elemento clave para la realización de tal tarea. La forma de asegurar estos deberes se convierte en el orden territorial español, obvio es decirlo, en especialmente problemático ${ }^{7}$.

Ahora bien, el reto de lograr una unidad de acción se complica aún más cuando a tal pluralismo se añade a su vez la apertura del Estado a procesos de integración como el acaecido en Europa desde la mitad del siglo pasado. Hay que determinar entonces la incidencia que la atribución de poderes de la Unión Europea tiene en la distribución de competencias entre el Estado central y las organizaciones políticas descentralizadas, en el Estado español, entre el Estado central y las Comunidades Autónomas. Y quizá pueda ser excesivamente simplista afirmar que, partiendo del conocido principio de autonomía institucional del derecho de la Unión Europea, no hay alteración posible.

Conforme a este principio, como es conocido, el ordenamiento europeo respeta las singularidades del Derecho interno incluso cuando se trata de desarrollar y dar aplicación a sus propias disposiciones. El proceso de integración europea respeta la forma estatal de organización del poder; solo exige que no afecte al deber de todo Estado miembro de lealtad comunitaria y a la garantía de la aplicabilidad y efecto directo del Derecho europeo. De hecho, la consecuencia de este «principio de indiferencia» del Derecho europeo respecto de la estructura interna del Estado miembro es que no cabe alegar por parte del Estado su estructura federal para justificar el incumplimiento de una obligación comunitaria. Justo la necesidad de compatibilizar estos dos principios, la garantía de que el proceso de integración no afecte al sistema de distribución de competencias del Estado, y la responsabilidad que éste también adquiere de cumplir su deber de lealtad comunitaria, produce especiales dificultades en Estados descentralizados.

Y es cierto que desde la perspectiva europea, la descentralización política de los Estados puede resultar, en definitiva, relativamente indiferente. Pero desde el punto de vista de los Estados miembros con descentralización política, la integración europea plantea al menos dos tipos de problemas, situados respectivamente en los ámbitos de la creación y de la aplicación del Derecho europeo; podemos encontrar un tercer problema en la responsabilidad financiera del Estado por incumplimiento de las obligaciones que impone el Derecho europeo.

Resulta oportuno, pues, atender a esta problemática. Y una forma de hacerlo quizá especialmente acertada pueda ser analizando la teoría y la realidad práctica

ducirse la conflictividad a acuerdo o consenso, CRUZ VILLALÓN, P., «La construcción jurisprudencial del Estado de las Autonomías», La curiosidad del jurista persa, y otros estudios sobre la Constitución, op. cit. pp. 467 ss.

$7 \mathrm{La}$ situación en que se encuentra entonces el Tribunal Constitucional que, como es conocido, ha de resolver la alta conflictividad existente en nuestro Estado Autonómico, provoca los lamentos conocidos, por ejemplo, del catedrático de Derecho constitucional y antiguo Presidente del Tribunal Constitucional, Pedro Cruz Villalón. 
de la norma jurídica europea que quizá se adecúa de mejor forma al pluralismo ordinamental que genera el proceso de integración europeo. La directiva, en efecto, postula que los órdenes europeo y estatal se articulen desde la cooperación; y resulta así especialmente respetuosa con los ordenamientos complejos como el nuestro ${ }^{8}$. Pero precisamente por ello su aplicación práctica es también especialmente problemática: el respeto y la garantía del difícil equilibrio que supone no resulta siempre fácil; aunque sí de la mayor importancia para asegurar, como habíamos analizado anteriormente, el pluralismo ordinamental de nuestro tiempo.

Por eso resulta especialmente sugerente la lectura del libro coordinado por Xabier Arzoz Santisteban, Trasposición de directivas y autogobierno. El desarrollo normativo del Derecho de la Unión Europea en el Estado Autonómico. Incide precisamente en el análisis de esta norma jurídica y en el desarrollo que tiene en la práctica: ¿hasta qué extremo su práctica es respetuosa con este pluralismo ordinamental? Como muy bien dice uno de los autores que participa en este volumen, la teoría es una y la práctica otra bien distinta: en la teoría partimos del conocido principio de la autonomía institucional, en la práctica se produce un dominio del Estado central en la transposición del Derecho de la Unión.

En la introducción de este muy extenso volumen, Xabier Arzoz incide ya en estas dos ideas señaladas: en primer lugar, en el sentido del principio de autonomía institucional, en segundo término, en que la directiva es el instrumento federal por excelencia de la Unión Europea. El estudio se centra así en la potencialidad que tiene esta norma jurídica, pero no desde cualquier perspectiva, sino desde la perspectiva constitucional; esto es, desde la óptica del análisis de las potencialidades de esta norma para articular jurídicamente el pluralismo en Europa. Pero la teoría ha de ser contrastada con la realidad práctica. La dialéctica teoría y realidad constitucional, que por cierto con gran fortuna da nombre a la Revista en la que se insertan estas letras, comprende pues la médula de las preocupaciones de los autores que escriben en este volumen. Los diferentes autores que colaboran en la redacción del libro, desde diversas perspectivas y ángulos, colaboran a dar coherencia y sistemática al estudio y exponen la dialéctica expresada, procurando extraer de ella sus mayores potencialidades. Xabier Arzoz expone ya en la introducción al libro el sentido y el alcance de la investigación: el trabajo, en sus propias palabras, se estructura en tres partes: estudio teórico, estudio comparado y analítico, y diagnóstico y propuestas de mejora.

Es cierto que resulta difícil dar coherencia y sistemática a un estudio de más de 550 páginas, en el que participan seis autores. Sin embargo, ya desde la introducción Arzoz deja bien claro al lector que no nos encontramos ante una yuxtaposición de estudios sobre la directiva; que en sí ya tendrían un valor considerable. Lo

8 «En la articulación entre ordenamientos a través de la creación del Derecho, al construir una específica relación cooperativa, la directiva desempeña una posición relevante», ALGUACIL GONZÁLEZ-AURIOLES, J., La directiva comunitaria desde la perspectiva constitucional, Madrid: Centro de Estudios Políticos y Constitucionales, 2004, p. 233. 
que todo jurista o ciudadano en estas lides hará bien en leer es un estudio sistemático y ordenado sobre el sentido y el alcance del desarrollo normativo del Derecho de la Unión Europea en nuestro Estado Autonómico; y ello a partir del estudio de la teoría y la práctica de la directiva europea. El estudio dogmático lo lleva a cabo Miguel Azpitarte Sánchez. A partir de la muy lúcida comprensión de los fundamentos constitucionales del proceso de integración europea, expresados ya en su propia tesis $^{9}$, examina los fundamentos europeos y constitucionales del ejercicio competencial de las Comunidades Autónomas. El estudio comparado lo realiza Héctor López Bofill: analiza los instrumentos y técnicas para el desarrollo normativo del Derecho de la Unión Europea en otros Estados compuestos de la Unión. El estudio empírico lo llevan a cabo tres autores: Tomás de la Quadra Salcedo Jannini centra su estudio en las directivas que inciden en la regulación económica. Alba Nogueira examina la incorporación al ordenamiento español de las directivas ambientales. José Manuel Pérez Fernández estudia la transposición al ordenamiento español de la Directiva 2006/123/CE relativa a los servicios en el mercado interior. El propio coordinador de la obra, Xabier Arzoz, dedica un capítulo final a reflexionar sobre el material elaborado y formular algunas conclusiones y propuestas.

Las limitadas pretensiones del comentario a este libro, que traen causa de las muy restringidas capacidades de quien lo escribe, hacen que centre las glosas en los capítulos escritos por Azpitarte, López-Bofill, de la Quadra, y Arzoz. Hará bien el lector, no obstante, en leer y comprender el libro entero; sólo así podrá aprehender en su totalidad el sentido de la teoría y la práctica de esta norma jurídica y los problemas que plantea en la realidad el respeto al delicado equilibrio en el que se fundamenta.

\section{EL ESTUDIO TEÓRICO}

Miguel Azpitarte Sánchez, Profesor Titular de Derecho constitucional (con perfil de Derecho de la Unión Europea) en la Universidad de Granada, analiza el contexto de la directiva, esto es, la razón de ser de esta norma jurídica. Parte en tal estudio de una realidad innegable: la unidad es un requisito existencial de todo ordenamiento; todo ordenamiento aspira al logro de tal unidad. Pero también de una particular forma de concebir la teoría de la democracia, que la vincula inexorablemente a la noción de pueblo; si en la Unión Europea no existe pueblo europeo, no cabe encontrar poder constituyente capaz de sustentar una hipotética Constitución europea. No alcanza a ver Azpitarte una teoría constitucional que la sustituya. Atrás queda, en sus propias palabras, el Tratado por el que se establece una Constitución para Europa. Parece coincidir así con las tesis que ya esbozó Grimm, a la sazón magistrado del Bundesverfassungsgericht, sobre el proceso de creación europea de

9 AZPITARTE SÁNCHEZ, M., El Tribunal Constitucional ante el control del Derecho comunitario derivado, Civitas, Madrid, 2002. 
Derecho $^{10}$. Tesis ciertamente polémicas, pues la nueva situación política en Europa podría plantear nuevos desafíos que difícilmente van a poder ser resueltos desde posiciones exclusivamente estatalistas ${ }^{11}$.

En cualquier caso, y a partir del presupuesto metodológico expuesto, entiende que la responsabilidad del Estado constitucional es una responsabilidad política, mientras que el de la Unión Europea es económica. La responsabilidad del Estado constitucional es el logro de la integración del pluralismo social. La responsabilidad de la Unión es la integración de los mercados nacionales. Esto implicaría la finitud del proyecto de integración, resulta lógico entonces que la famosa cláusula de «la competencia de la competencia» radique en el Estado. Y precisamente por ello se hace más necesario respetar la autonomía institucional; si bien puede leerse en relación dialéctica con la cooperación leal entre ordenamientos, su garantía resulta de la mayor importancia para asegurar el respeto a la distribución competencial entre Estado y Comunidades Autónomas. Bien puede el imponderable de cumplir con el Derecho de la Unión motivar el reconocimiento de un poder de sustitución del Estado central; la necesidad de asegurar el reparto competencial y de que la incidencia del Derecho de la Unión Europea no trastoque tal reparto podría justificar el blindaje de ciertas competencias realizadas en las reformas estatutarias iniciadas en la primera legislatura del Gobierno de Rodríguez Zapatero.

Existe no obstante en su opinión un tercer escenario: y es proyectar la garantía del cumplimiento de la normativa europea, no en la práctica asunción de ésta por el Estado, sino en el respeto del reparto competencial en su ejecución, apelando al

10 GRIMM, D., «¿ Necesita Europa una Constitución?», Debats n 55, 1998, p. 13. Señalaba también IPSEN ya en 1972 que « la religión, la raza, el nivel cultural, la conciencia histórica y los factores de cohesión nacional dificultan la formación de una integración política», Europäisches Gemeinschaftsrecht, Tübingen: JCB Mohr, 1972. pág 1001 KIRCHHOF opina que «con la pérdida de la estatalidad se extinguirán las garantías constitucionales», «Europäische Einigung und der Verfassungsstaat der Bundesrepublick Deutschland», ISENSEE, J. (ed), Europa als politische Ideeund als rechtliche Form, 1993, p. 84. Aun cuando, al día de hoy, la afirmación sea acertada, no por ello debemos olvidar que quizá aun con la propia estatalidad las garantías constitucionales se encuentren hoy en día amenazadas, así VEGA, P. Mundialización y Derecho Constitucional. La crisis del principio democrático en el constitucionalismo actual», Revista de Estudios Políticos (nueva época) $n^{\circ} 100,1998$, p. 54.

11 LÓPEZ PINA, «De la idealización del Estado», Saber Leer n 36, 1990, p. 5. El propio DE VEGA, al referirse al fenómeno de la mundialización económica, realidad que se encuentra en íntima conexión con el proceso de integración europea, entiende que « lo que el Derecho Constitucional en ningún caso puede hacer es seguir operando con los mismos esquemas del pasado como si el pavoroso fenómeno de la mundialización económica no se estuviera produciendo», «Mundialización y Derecho Constitucional. La crisis del principio democrático en el constitucionalismo actual», op. cit., p. 54. Opina en este sentido CORCUERA que «no es problema que la construcción de Europa pueda hacer desaparecer los Estados, ni que las lealtades más significativas dejen de ser las nacionales. El problema es garantizar la existencia de una inspiración constitucional (...) en la serie de procesos económicos, institucionales e incluso ideológicos que están construyendo esa integración», Prólogo a RUIPÉREZ, J. La Constitución Europea y la problemática del poder constituyente. Algunas reflexiones críticas desde el Derecho Político, Madrid: Derecho. Biblioteca Nueva, 2000, p. 16. Afirma así RUIPÉREZ que, frente al principio de las nacionalidades del siglo XIX «en la actualidad (...) se entiende que, dado el desarrollo político, social y, sobre todo y ante todo, económico, el Estado nacional resulta insuficiente para atender a las nuevas demandas de los individuos y que, por ello mismo, se hace necesario ampliar los espacios de actuación», p. 33. 
principio de responsabilidad de la Administración competente en caso de incumplimiento $^{12}$. Tal tesis la desarrolla en el segundo capítulo que escribe en el libro: «La distribución interna de responsabilidad por incumplimiento del Derecho de la Unión». ¿Es necesario arbitrar procedimientos que ayuden a delimitar el deber de pago del Estado central o de las Comunidades Autónomas? En su opinión, el ordenamiento vigente puede ofrecer un camino: la reclamación administrativa de responsabilidad patrimonial y, de ser necesaria, su subsiguiente judicialización. Apela al Real Decreto 515/2013, de 5 de julio, por el que se regulan los criterios y el procedimiento para determinar y repercutir las responsabilidades por incumplimiento del Derecho de la Unión Europea (BOE de 6 de julio de 2013).

\section{LOS ESTUDIOS COMPARADO Y EMPÍRICO}

Héctor Lopez Bofill, profesor Ayudante de Derecho constitucional en la Universidad Pompeu Fabra, observa cómo el derecho de la Unión ha condicionado de forma relevante la evolución del pluralismo normativo existente en el seno de los Estados miembros. Los modelos en que la incorporación normativa de rango constitucional se encuentra más desarrollada aportan una mayor certidumbre en la descripción del rol de los entes territoriales; se encuentra más perfilado en Alemania, Austria e Italia; algo perfilado en Bélgica; y nada perfilado en España. Concluye destacando cómo en todos los sistemas estudiados existe la preocupación por mantener espacios de decisión que las normas constitucionales internas de distribución de competencias atribuyen a los entes territoriales. El problema de fondo estriba en los déficits globales del sistema constitucional interno en lo que se refiere a la estructura de la organización territorial.

Tomás de la Quadra-Salcedo Jannini, Profesor Titular de Derecho constitucional en la Universidad Autónoma de Madrid, aborda el delicado estudio de la transposición de las directivas que inciden en la regulación económica. Experto en Derecho constitucional, ha defendido con profundo rigor una tesis original y ciertamente polémica: que la Constitución española de 1978 no impone el mantenimiento del mercado nacional único, aunque lo habilita ${ }^{13}$. La garantía política de

12 De forma paralela a la crítica que desde una perspectiva constitucional cabe realizar a las denominadas directivas detalladas y al propio efecto directo de las directivas: pervierten la noción de directiva. La falta de cumplimiento del delicado equilibrio que representa la directiva y que da alas al fomento de las directivas detalladas y el efecto directo de las mismas bien pudiera ser sustituida por el la aplicación estricta del principio de responsabilidad del Estado miembro incumplidor de su tarea de incorporar la misma en plazo, cfr, ALGUACIL GONZÁLEZ-AURIOLES, J., La directiva comunitaria desde la perspectiva constitucional, op. cit., pp. 142 ss.

13 Mercado Nacional Único y Constitución, Madrid: Centro de Estudios Políticos y Constitucionales y Fundación Manuel Giménez Abad, 2008. En su opinión, el grado de equilibrio entre autonomía y unidad no se encuentra fijado realmente en la Constitución, ni siquiera en el bloque de la constitucionalidad, es variable en el tiempo. La determinación, en cada momento histórico, de cuánta unidad o de cuánta autonomía es necesaria no debiera ser una determinación jurídica, sino política; que a través de la potestad que tiene el Estado de determinar lo básico, debe corresponder a las Cortes Generales, y no a un órgano jurisdiccional, p. 219. 
la descentralización, que Cruz Villalón tanto echa de menos en el orden territorial español, podría radicar en las Cortes Generales.

En su opinión, es posible corroborar el importante uso que se hace, por parte del Estado, del título competencial transversal del Estado sobre bases y coordinación de la planificación general de la actividad económica. Esta competencia permitiría al Estado desarrollar y aplicar incluso aquellas normas europeas que reglamentan materias de competencia exclusiva de las CC.AA; se produce con ello el tránsito de actividades como la agricultura a la economía, y así de la exclusividad (autonómica) a la compartición (con el Estado). Por lo demás, en su opinión, la consecuencia de la amplia interpretación jurisprudencialmente realizada del alcance de la competencia sobre ordenación general de la economía ha sido la restricción de la capacidad autonómica de adoptar políticas propias en materia económica. Comprende así que los nuevos Estatutos de Autonomía hayan tratado de limitar la expansión ilimitada del poder normativo del Estado_ - el Estatuto de Cataluña.

\section{EL DIAGNÓSTICO Y LAS PROPUESTAS DE MEJORA}

Como señalábamos anteriormente, Xabier Arzoz, Profesor Titular de Derecho Administrativo en la Universidad del País Vasco, y coordinador de la obra, al hilo de los estudios realizados en la misma, expone unas conclusiones especialmente lúcidas. A la luz de lo examinado, procede constatar en primer lugar que en el proceso de integración europea, con relación a la incorporación al ordenamiento interno de las directivas, se ha producido de facto un importante desplazamiento competencial a favor del Estado. La primera razón la encuentra en el detalle de las directivas. Ahora bien, ¿por qué es una tarea ingrata para las CC.AA. y no, en cambio, para el Estado? ¿No debería provocar justo lo contrario? Esto es, que la trasposición fuera por parte de las CC.AA. La segunda razón estriba en la coincidencia entre directiva y norma básica. En cualquier caso, hay que tener en cuenta, en su opinión, que descentralización política e integración europea son dos procesos aparentemente contradictorios que se solapan en el tiempo pero que tienen distintos ritmos y condicionantes. $\mathrm{Y}$ a continuación expone quizá una de las conclusiones más importante que cabe extraer de este libro: es necesario recuperar el respeto de la distribución constitucional y estatutaria de competencias en el ámbito de la trasposición de las directivas.

Arzoz, por lo demás, rechaza la tesis defendida por Daniel Sarmiento: la estructura territorial descentralizada no forma parte necesariamente de la identidad nacional. Por eso tiene sentido que los nuevos Estatutos de Autonomía contengan disposiciones específicas que reiteren que la regla de la integración europea no altera la distribución interna de las competencias. Con las reformas estatutarias, el criterio de sustitución de la relación bases-desarrollo por la de directiva-desarrollo autonómico ha sido acogido expresamente por el bloque de la constitucionalidad. Solamente cuando la norma europea no haya agotado el ámbito de lo básico, le corresponde al Estado adoptar las normas necesarias para completar la legislación bá- 
sica. Afirma así con rotundidad que las Comunidades Autónomas pueden y deben transponer las directivas europeas hasta donde llegue su competencia normativa... sin necesidad de esperar a la intermediación estatal. Los órganos centrales del Estado también pueden transponer las directivas europeas; si no lo considerasen necesario sería conveniente que lo anunciaran. Pero si los órganos centrales del Estado optan por adoptar nuevas normas básicas, deberían dejar un plazo de tiempo prudencial a las Comunidades Autónomas para que adaptasen sus normas de desarrollo.

\section{A MODO DE CONCLUSIONES}

En unas determinadas circunstancias históricas, como observa González Encinar, resultó indudable que la aliada de la democracia fue la centralización: «la lucha contra los privilegios del Antiguo Régimen obligó en su momento al liberalismo revolucionario a suprimir todo tipo de cuerpos intermedios entre el individuo y el Estado en defensa del principio democrático de la igualdad ${ }^{14}$. Hoy, sin embargo, la descentralización no supone la creación de cuerpos intermedios entre el individuo y el Estado, sino que es la propia organización política la que se organiza territorialmente ${ }^{15}$. Por lo demás, una de las ideas medulares del constitucionalismo, acuñada ya por Montesquieu, se basa en que la libertad se asegura mejor distribuyendo el ejercicio del poder público. De forma complementaria, bien podríamos decir que la garantía de ciertas peculiaridades políticas propias de algunos territorios, se asegura impidiendo la acumulación de todo el poder público en manos de las instituciones centrales, reservando a entidades descentralizadas ciertas atribuciones. La conexión entre ordenamiento democrático y estructura federal nos la hizo ver Hesse de forma particularmente lúcida en su clásico Estado federal unitario ${ }^{16}$.

Ahora bien, habíamos visto cómo toda estructura federal requiere de un principio de lealtad entre entes descentralizados; tal lealtad crea márgenes para el desarrollo del principio de cooperación entre entes descentralizados entre sí y entre ellos y la Federación. Uno de los elementos básicos de toda estructura descentralizada es el principio de cooperación; resulta lógico que, como señalaba López Pina ${ }^{17}$, se haya

14 GONZÁLEZ ENCINAR, J.L, El Estado Unitario-Federal, Madrid: Tecnos, 1985, pp. 159, 160.

15 GONZÁLEZ ENCINAR, J.L., El Estado Unitario-Federal, op. cit., p. 159.

16 Tal conexión se evidencia en que el Estado descentralizado «habilita que partidos minoritarios en la Federación puedan ser partidos de gobierno en los (entes descentralizados), donde son partidos mayoritarios (...) A minora la contraposición entre partidos de gobierno y partidos de oposición en la medida en que los equilibrios políticos de los (entes descentralizados) puedan ser distintos. A los partidos en la Federación, los (entes descentralizados) les abren el camino de la responsabilidad de gobierno y la posibilidad de una línea propia, de modo que no se limite a la crítica del partido de gobierno - lo que no deja de tener un gran significado para la psicología de los partidos. Sobre todo, permite que los líderes de la oposición aprendan a valorar los asuntos de Estado y se habitúen a la responsabilidad de Estado, de manera que cuando sean el partido de gobierno en la Federación, dispongan de un amplio personal político a su disposición», «El Estado Unitario Federal», op. cit, p. 25.

17 LÓPEZ PINA, A. «Del principio de subsidiariedad como límite al ejercicio de las competencias en la Unión Europea», op. cit., p. 11. 
convertido también en el elemento básico del orden jurídico-político de la Unión Europea; la directiva europea es la norma jurídica que mejor se adecúa a tal principio cooperativo y está llamada a ser pues la principal fuente del Derecho del nuevo orden. Justo porque otorga la posibilidad de interconectar el pluralismo ordinamental en Europa. Del respeto al delicado equilibrio en que se configura dependerá el logro de tal interconexión. Libros como el coordinado por Xabier Arzoz Santisteban inciden en el análisis de tal delicado equilibrio y aportan los elementos necesarios para tomar conciencia de la necesidad de retomar ciertos equilibrios perdidos. Konrad Hesse defendió desde un principio en clave federal la descentralización territorial en Alemania y subrayó los instrumentos que a su juicio son necesarios para llevar a buen puerto tal proyecto jurídico-político ${ }^{18}$. El vigente constitucionalismo no puede comprenderse sin atender a su relación con el proceso de integración europea, como el propio Hesse observó reiteradamente. Urge así atender a las posibilidades de configurar el nuevo constitucionalismo europeo en tal clave federal: la directiva europea puede ser el instrumento normativo adecuado para ello. Xabier Arzoz aporta, con el libro objeto glosa en estas humildes páginas, un estudio serio y riguroso de las potencialidades teóricas y prácticas de tal instrumento normativo; nos introduce pues en las posibilidades teóricas y prácticas de configurar jurídicamente en clave federal la vigente realidad constitucional europea.

$* * *$

TiTlE: A bout the articulation of legal orders in the European Union. With regard to the book Transposition of directives and self-Government coordinated by Xabier Arzoz Santisteban.

ABSTRACT: The work subject of comment is directed by Arzoz Santisteban and focuses on analyzing the potential that has the directive to articulate ordinamental pluralism generated by the process of European integration in our territorial order. But the theory bas to be contrasted with the practical reality. It is very interesting to read this book because it affects precisely in this legal standard and analysis the development that has in practice: is really their practice friendly with this ordinamental pluralism? The truth is that as it is revealed in the book on the theory we start from the known principle of institutional autonomy, the practice may attached to produce a domain of the central State in the transposition of the EU law.

Resumen: La obra objeto de comentario es dirigida por Arzoz Santisteban y se centra en analizar las potencialidades que tiene la directiva para articular el pluralismo ordinamental que genera el proceso de integración europea en nuestro orden territorial. Pero la teoría ha de ser contrastada con la realidad práctica. La lectura de este libro es muy sugerente pues incide precisamente en el análisis de esta norma jurídica y del desarrollo que tiene en la práctica: ¿ hasta qué extremo su práctica es respetuosa con este pluralismo ordinamental? Lo cierto es que como se pone de manifiesto en el libro en la teoría partimos del conocido principio de la autonomía institucional, en la práctica podri allegar a producirse un dominio del Estado central en la transposición del Derecho de la Unión.

KEY WORDS: Ordinamental pluralismo, procees of european integration, principle of institutional autonomy, directives transposition.

Palabras Clave: Pluralismo ordinamental, proceso de integración europea, principio de autonomía institucional, transposición de directivas.

FECHA DE RECEPCIÓN: 10.05.2014 FECHA DE ACEPTACIÓN: 30.07.2014

18 El Estado unitario federal. 